\title{
The BMA's Torture Report and afterwards
}

\author{
John Dawson British Medical Association, London, UK
}

\section{Editor's note}

Sadly, Dr Fohn Dawson died on the 20th of December 1990. For many years Dr Dawson had extensive interest and involvement, via his position at the British Medical Association, with a number of national and international groups devoted to tackling the problems associated with 'torture and the medical profession'. He was instumental in the production of the first BMA Torture Report and, at the time of his death, was working closely with a BMA working party on a further report.

The following is a transcript of the talk given by $\mathrm{Dr}$ Dawson at the XIX Tromsø Seminar in Medicine on Torture and the Medical Profession. Had Dr Dawson lived, he would have submitted a manuscript based on his talk. In the circumstances, it has been decided to submit the transcript with minimal editing.

It took two to three years before a resolution was passed at our annual meeting calling on the BMA to consider the question of torture and doctors' involvement in it. That resolution was passed in 1984 and we produced the report in 1986 (1). The Torture Report showed that torture happens in an increasing number of countries. Of course, you know that. But remember that the great majority of the doctors in the United Kingdom, or in France, or in The Netherlands, do not feel so bound up or so concerned by the issues that concern you. An important part of the report was to try to make the question of doctors' involvement in torture relevant to ordinary doctors - not campaigners or people who care like you.

So, it was not just a question of wringing our hands and saying 'Isn't it awful'. We wanted to do something practical to try to reduce the ways in which doctors might be involved. This approach was successful in persuading the senior staff and the elected officers of the British Medical Association that the question of doctors' involvement in torture is a subject that you can care about and, where possible, take action. Particularly, it is possible for national medical associations to take action.

One of the practical elements of the report's conclusions was that there should be consistent international standards of ethics.

We suggested that national medical associations should ratify the Declaration of Tokyo because in that way we share common standards which we can understand and apply internationally.

Secondly, we suggested you shouldn't give anybody medical skills and knowledge without at the same time putting them into a framework of ethics that will constrain the way in which those skills and knowledge are used.

Finally, we talked about the distance between the doctors and the state. This, I think, is crucially important. For example: Does your country provide for independent autopsies of people who have died in custody? Do doctors perform intimate body examinations for the police? Or virginity tests for immigration authorities?

Both in the BMA's handbook on medical ethics (2) and in The Torture Report, we talk about the duty to inform on activities breaching the Declaration of Tokyo. We say that this duty transcends any question of national security. If a doctor knows of some activity breaching the Declaration of Tokyo, then the doctor has a duty to speak out and, in so doing, create a distance between the doctors and the state.

I understand that the report has been successful and we are pleased with that. But you can't simply stand still on the basis of having produced one report. So we are taking a second look at this issue and we will make the report still more effective.

There is one new area that I want to talk about today.

I feel that there are a number of countries which have fallen into abuses of human rights and have then made the transition back to non-violent societies in which the rights of individuals are honoured and protected. I don't know whether you remember, but in England Uruguay used to be known as the Switzerland of South America - a stable middle-class, a good social welfare system. How can a country like that decline into the abuses of human rights that were common during the 1970s? If it could prove possible to determine that a society was about to enter a stage in which human rights would be violated and in which the Declaration of Tokyo would be breached routinely, then it should be possible for national medical associations, individuals and other groups to protest and to act to halt that slide away from the standards that we consider desirable. 
So, we are looking for the early indicators of a society in decline, a society about to go wrong. It may be that there is a pattern that we can establish. For example, it seems that for a society to be about to go wrong in human rights terms, you need a minority group, not perhaps just a racial or religious minority. Remember the miners in England in the mid-1980s and the way in which the government decided they were a group that had to be taken on? Additionally, I think you would look for a society with serious inequalities in wealth or material possessions between one group and another group.

You might look for a political police force - a police force that was not independent of national politics but which actually supported one political party or another. You might look for indications that the media, either electronic in terms of radio and television, or printed, had a consistent bias towards one part of the political spectrum. It might be that in these countries there is no tradition of, or legislation for, freedom of information. The accountability of doctors and other professionals to organisations independent of the state is obviously important. In the educational system from secondary school age (and by that I mean 12 years) up to the end of higher education at perhaps age 25 , one should be looking for independence from the state in terms of the curriculum and examinations.

There are many detailed indicators that we shall have to research including, for example, the rules for reporting and investigating deaths in custody, how long a person can be detained by police before judicial approval of that detention is necessary, and even perhaps whether or not journalists are permitted by the courts to protect the sources of their information.

We may find small indicators which are comparable from country to country and which form a pattern. If we can find a pattern then I think it should be possible to produce a checklist. This checklist would allow people who care about human rights to see whether or not a country was in the early stages of something going wrong. The earlier you can pick up this trend, then the easier it should be for organisations such as national medical associations to raise the alarm and to try to put a stop to the departure from international standards.

If we are successful in finding a pattern then that will $\vec{v}$ be, I hope, another practical contribution to trying to limit doctors' involvement in torture. And it is these practical issues that we are most concerned about at the BMA.

Fohn Dawson, $M B, B S$, was Head of the Professional, Scientific and International Affairs Division of the British Medical Association, London, UK.

\section{References}

(1) Working party of the British Medical Associatio investigating the involvement of doctors in torture. Then torture report. London: BMA, 1986.

(2) BMA. Philosophy and practice of medical ethics. London: BMA, 1988. 